\title{
Psicologia Comunitária e Programa de Saúde da Família: Relato de uma Experiência de Estágio
}

Community psychology and family health program: report of an internship experience

Carlos Alberto Pegolo da Gama Mirna Yamazato Koda

Universidade São Francisco - Itatiba

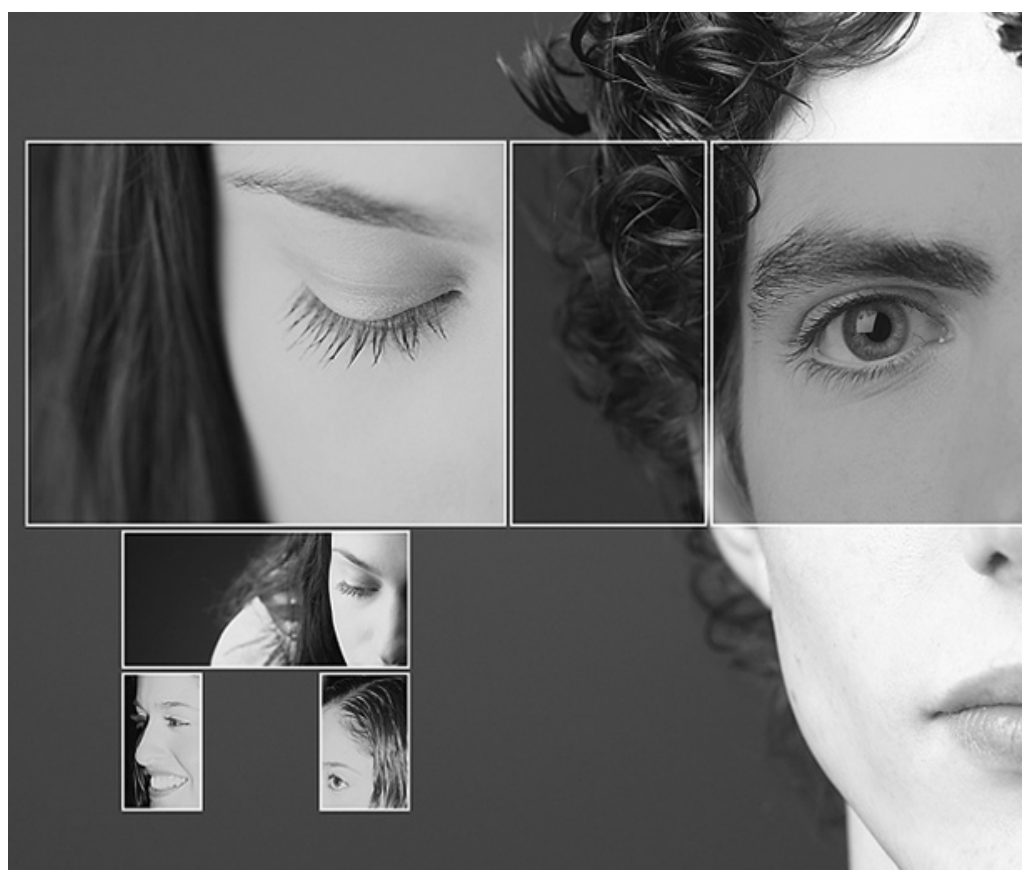


Resumo: O presente artigo relata o trabalho realizado a partir de um campo de estágio da Psicologia Comunitária, desenvolvido no Programa de Saúde da Família de um Município do interior paulista. Refletimos sobre o papel da Psicologia no PSF, buscando construir ações afinadas com o campo da saúde pública. Apresentamos o processo de constituição da parceria entre Universidade e Secretaria de Saúde bem como as atividades realizadas no estágio. O trabalho dos estagiários abarcou tanto as intervenções junto aos pacientes da unidade como junto à equipe do PSF. A experiência evidenciou a importância do trabalho da saúde mental no PSF, principalmente no que diz respeito ao estabelecimento de uma lógica preventiva e de promoção à saúde. Procuramos, assim, contribuir com o desenvolvimento de ações no campo da Psicologia Social Comunitária.

Palavras-chave: Programa de Saúde da Família. Saúde mental. Psicologia Comunitária. Prevenção e promoção à saúde.

\begin{abstract}
The present article describes the work derived from a Community Psychology internship field carried out in the Family Health Care Program (FHCP) in a city located in the state of São Paulo, Brazil. We discuss the role of Psychology in the FHCP with the purpose of forming actions which are relevant to the field of public health. We present the constitution process of partnership between the University and the Health Department as well as the activities held during the internship. The interns' work encompassed the interventions with the patients of the unit and also with the FHCP staff. The experience has evidenced the importance of the work with mental health in the $\mathrm{FHCP}$, especially in regard to the organization of a preventive and promoting health program. Thus we hope to contribute to the development of actions in the field of the Social Community Psychology.
\end{abstract}

Keywords: Family Health Care Program. Mental health. Community Psychology. Prevention and health promotion.

\title{
O psicólogo na saúde pública
}

A inserção do psicólogo na área da saúde pública está presente na pauta de discussões do Conselho Federal de Psicologia e de suas representações regionais. Recentemente, o Sistema Conselhos organizou um processo de reflexão a respeito do tema que envolvia toda a categoria e que culminou com a realização do I Fórum de Psicologia e Saúde Pública, em outubro de 2006. Essa iniciativa, dentre outras, tem por objetivo aprofundar o conhecimento e a participação da Psicologia em tal setor e também organizar e direcionar a questão da formação dos profissionais.

Por outro lado, na área governamental, assistimos à criação da Comissão Interministerial de Gestão do Trabalho e Educação na Saúde, através do Decreto presidencial de 20 de junho de 2007, que tem função consultiva sobre a ordenação da formação de recursos humanos na área da saúde, levando-se em conta as proposições do Sistema Único de Saúde. Essa iniciativa busca fortalecer a formação e o trabalho dos profissionais da saúde na construção do SUS e reforça, dentre outras questões, a importância da aproximação e da articulação entre os cursos de graduação e a saúde pública.

A configuração do campo de trabalho do Psicólogo nessa área vem acontecendo paulatinamente nas últimas décadas, e tem 
A participação de psicólogos na saúde pública inicia-se no final da década de 70, no bojo das transformações que aconteceram nas políticas públicas naquele momento provocado muitos debates e mudanças no âmbito da Psicologia. Segundo Spink (2003),

A grande virada, no que diz respeito à inserção dos psicólogos nos serviços de saúde, em São Paulo, ocorreu a partir de 1982, com a adoção de uma política explícita por parte da Secretaria de Saúde, de desospitalização e de extensão dos serviços de saúde mental à rede básica. (p. 31)

De acordo com o Cadastro Nacional de Estabelecimentos de Saúde, em abril de 2006, havia, no Brasil, 14.407 profissionais de Psicologia trabalhando na rede de serviços de saúde. Isso corresponde a aproximadamente $10 \%$ da categoria (Spink, 2007).

A participação de psicólogos na saúde pública inicia-se no final da década de 70 , no bojo das transformações que aconteceram nas políticas públicas naquele momento. Em 1978, tem lugar, em Alma Ata, a 1a Conferência Internacional sobre Atenção Primária em Saúde, em que o Brasil e outros países assumem o compromisso de aumentar a cobertura da atenção básica à população. O objetivo era implantar um programa nacional de serviços básicos de saúde que funcionaria como porta de entrada de um sistema unificado e hierarquizado de saúde. Essas propostas, aos poucos, vão sendo implementadas e são encampadas na Constituição de 1988 através da implantação do SUS.

Dentro desse processo, que enfatiza o fortalecimento de ações preventivas e do trabalho em equipes multidisciplinares, abrese a oportunidade de a Psicologia e de outras profissões de saúde se inserirem no campo da saúde pública, em busca da construção de um modelo que se desloque de um foco curativo centrado na figura do médico. Essas equipes vão, aos poucos, sendo constituídas nas Unidades Básicas de Saúde (UBS). São criados também ambulatórios de saúde mental com equipes multidisciplinares, que comporiam o nível secundário da atenção.

Dimenstein (1998) vai apontar outros fatores que contribuem para a aproximação entre Psicologia e saúde pública: a grave crise econômica e social que o País atravessa na década de 80, que reduz o poder aquisitivo da classe média e, em conseqüência, o mercado de atendimentos privados; o crescente número de profissionais formados na Universidade, que provoca um excesso de oferta de serviços privados de Psicologia; o início da produção de uma cultura psicológica no Brasil e as críticas à categoria por priorizar as camadas sociais mais abastadas, já que isso reforça um discurso ideológico que ignora o contexto e as contradições sociais.

Spink (2003) afirma que o processo de constituição das equipes multidisciplinares e sua inserção na atenção básica enfrentou diversas dificuldades: os profissionais que tradicionalmente trabalhavam na área da saúde não compreendiam o papel desses novos atores, e estes, por sua vez, não possuíam uma noção exata a respeito de sua função. Nesse momento, ficam claras as dificuldades do psicólogo para dar conta desse novo campo, pois sua formação e atuação ainda estavam muito pautadas no modelo da clínica privada individual.

Tal modelo de trabalho do psicólogo privilegia uma atuação como profissional liberal, em consultórios particulares, com uma clientela oriunda de segmentos sociais de maior poder aquisitivo. São realizadas atividades de psicodiagnóstico ou psicoterapia, apoiadas num enfoque intra-individual, que enfatizam processos psicológicos e psicopatológicos com uma concepção de indivíduo abstrata e a-histórica. Essa atuação está muito ligada à tradição médica, em que a questão do saber 
e da autoridade na relação com o paciente não é questionada (Conselho Federal de Psicologia, 1994).

O contato com a saúde pública coloca o profissional diante de uma nova realidade, na qual a clientela tem baixo poder aquisitivo, apresenta demandas muito ligadas às suas condições econômicas e sociais, na maioria das vezes, muito diferentes da realidade do profissional.

A própria formação do psicólogo apresenta características que dificultam a construção de práticas que transformem o modelo tradicional de assistência. Segundo Spink (2003),

É pouco freqüente, no treinamento do psicólogo, a introdução de temas macrossociais que possibilitem uma discussão das determinações econômicosociais dos fenômenos psicológicos. A incorporação do social se dá, portanto, de forma reducionista, atendendo-se muitas vezes a categorias estanques como classe social, o que, embora permitindo a manipulação estatística das variáveis, não contribuem para a compreensão do social como processo. (p. 34)

Concomitantemente à inserção do psicólogo nas unidades básicas e nos ambulatórios, começam a ocorrer, de modo mais contundente, questionamentos com relação à atenção dada aos doentes mentais. Até a década de 80, o tratamento a eles reservado era a internação em hospitais psiquiátricos. Os psicólogos que trabalhavam nos manicômios ocupavam um lugar secundário, subordinado à figura do médico e geralmente restrito à avaliação psicodiagnóstica (Conselho Federal de Psicologia, 1994).

Em meados da década de 80, temos a formação do Movimento de Luta Antimanicomial (MLA). O MLA parte do princípio de que o termo manicomial não diz respeito unicamente à instituição hospital psiquiátrico, mas estende-se ao próprio funcionamento social que sustenta esse tipo de instituição assim como às relações de exclusão e de estigma. A questão da cidadania ganha lugar central no movimento.

Temos, com o MLA, o questionamento da compreensão do conceito saúde/doença mental e dos saberes a ele atrelados bem como a construção de uma rede de serviços territoriais que constituem espaços de sociabilidade, de trocas e de produção de subjetividades, efetivamente substitutivos ao modelo manicomial (Amarante, 1998, 1999). Os psicólogos, com outras categorias profissionais, usuários e familiares, têm participação ativa no MLA.

Aos poucos, vai se delineando uma política pública de saúde mental com a criação dos chamados equipamentos substitutivos, formados pelos Centros de Atenção Psicossocial (CAPS), as residências terapêuticas, os centros de convivência, as oficinas abrigadas de trabalho e as enfermarias psiquiátricas em hospital geral. Abre-se ao psicólogo um novo campo de trabalho, que coloca novamente o desafio de transformação de sua própria prática (Fernandes, Vicentin \& Vieira, 2004). Nesse contexto, é exigida dos profissionais envolvidos uma mudança de paradigma com relação às práticas desenvolvidas, mudança que reformule o olhar sobre o sujeito e seu sofrimento. Isso implica uma abertura para diferentes discursos que se afetam mutuamente na invenção de uma nova prática em saúde mental que supere o modelo manicomial (Amarante, 2000).

As políticas de saúde mental no Brasil têm priorizado o atendimento de pacientes com quadros de sofrimento psíquico mais graves, sendo que, com relação aos problemas menos severos, cabe o desafio de se construir uma rede de assistência mais sistematizada, que tenha como horizonte a implantação 
de políticas públicas mais abrangentes nos cuidados com a saúde mental.

\section{O programa de saúde da família}

A partir de 1993, o Ministério da Saúde adota, como estratégia para a atenção básica, o Programa de Saúde da Família (PSF), que se caracteriza como uma tentativa de promover a transformação do modelo tradicional de atenção à saúde. Tal programa busca aproximar as ações do território ao fortalecer o vínculo entre equipe de saúde e população e o trabalho de prevenção de doenças e a promoção da saúde. Ele tem sido implementado em um número cada vez maior de municípios brasileiros, configurando-se em importante dispositivo na atual política de saúde pública nacional. Segundo dados de 2006, o PSF está em funcionamento em 5.106 municípios, num total de 26,7 mil equipes, e cobre $46,2 \%$ da população brasileira, o que corresponde a cerca de 85,7 milhões de pessoas (Ministério da Saúde, 2007).

Conforme portaria do Ministério da Saúde, as equipes de saúde da família são compostas por pelo menos um médico generalista, um enfermeiro, um auxiliar de enfermagem e de quatro a seis agentes comunitários de saúde. Cada equipe de saúde da família deve acompanhar de 600 a 1000 famílias, não ultrapassando um total de 4500 pessoas atendidas (Brasil, 1997). Outros profissionais como, por exemplo, o psicólogo - podem ser incorporados à equipe ou constituir equipe de apoio, de acordo com as possibilidades e necessidades locais.

Andrade e Araújo (2003) afirmam:

O Programa do Ministério da Saúde denominado Programa de Saúde da Família (PSF) - é uma prática social que se diz inovadora quanto à pretensão de romper com os modelos tradicionais de atendimento e propor uma aproximação dos técnicos com a população para que, efetivamente, haja a promoção da saúde. Trata-se de uma proposta que pretende um deslocamento do lócus poder/saber na medida em que objetiva a participação coletiva na produção de saúde. Ou seja, propõe que a própria comunidade, aliada aos profissionais, produza modos de existência cotidianos resolutivos das dificuldades enfrentadas e geradores de qualidade de vida. (p. 75)

Ao considerarmos o PSF, no entanto, devemos atentar para o fato de que, se, por um lado, as políticas públicas no Brasil introduzem, no interior do próprio aparelho do Estado, questões importantes a respeito dos setores mais vulneráveis da sociedade, elas, historicamente, têm funcionado como um colchão amortecedor dos conflitos sociais (Spink, 2003), e respondem, muitas vezes de forma paliativa, aos problemas. Nesse contexto, há sempre o risco de se usar os conhecimentos técnicos da Medicina e da Psicologia para a reprodução de um certo discurso hegemônico normatizador, que culpabiliza o sujeito pela sua situação (Andrade \& Araújo, 2003).

A inserção do psicólogo no PSF é tema de debates e divergências. Ao se discutir tal ponto, inevitavelmente nos defrontamos com os aspectos históricos desse processo, na medida em que a prática psicológica continua apresentando dificuldades relativas ao trabalho na saúde pública. Tal panorama configura um campo rico e complexo, ao colocar a Psicologia num diálogo não só com outras disciplinas parceiras no campo da saúde como também com um contexto político social mais amplo.

O presente artigo busca discutir a atenção à saúde mental dentro da proposta do PSF a partir da experiência de um campo de estágio de Psicologia Comunitária, nas Unidades 
O Programa do

Ministério da Saúde

- denominado

Programa de

Saúde da Família

(PSF) - é uma

prática social

que se diz

inovadora quanto

à pretensão de

romper com

os modelos

tradicionais de

atendimento

e propor uma

aproximação dos

técnicos com a

população para

que, efetivamente,

haja a promoção

da saúde. Trata-se

de uma proposta

que pretende um

deslocamento

do lócus poder/

saber na medida

em que objetiva

a participação

coletiva na

produção de saúde. de Saúde da Família de um Município do interior de São Paulo. Esse campo de estágio foi iniciado em agosto de 2003, a partir da formulação de um convênio entre a Universidade São Francisco (USF) e a Secretaria de Saúde do Município.

Historicamente, a saúde tem sido uma importante área de atuação da Psicologia Comunitária. Ela trabalha no sentido de desenvolver ações de promoção da saúde, tendo como pano de fundo a noção de autonomia e cidadania. O papel do psicólogo deixa de ser unicamente de aspecto curativo e passa a ser de agente facilitador e potencializador de diversas formas de protagonismo social (Campos, 2000; Campos \& Guareschi, 2000).

\section{A implantação do estágio}

O convênio entre a Universidade e a SMS contemplou a implantação de um campo de estágio de Psicologia Comunitária no PSF do Município. Inicialmente, foram realizadas diversas reuniões com o Secretário e o diretor de saúde do Município, a coordenadora do PSF, as coordenadoras da Unidade do PSF e a coordenadora do Curso de Psicologia. Essas discussões com os gestores foram muito importantes, pois permitiram um espaço de interlocução privilegiado, que possibilitou a constituição de uma intervenção mais complexa no âmbito da atenção à saúde do Município, como, por exemplo, a criação de um CAPS-escola e a participação de representantes da Universidade no Colegiado de Saúde Mental do Município. Esse colegiado, integrado por diferentes atores envolvidos no setor, tem como objetivo discutir questões referentes a tal área a fim de fomentar a articulação de projetos.

As reuniões serviram para delinear uma proposta inicial de trabalho, e foi esclarecido aos gestores e técnicos da prefeitura que a Universidade não apresentaria um projeto definido a priori (Freitas, 1998). Em vez disso, ele seria construído junto às equipes de saúde, considerando as demandas da comunidade e um conhecimento mais particularizado sobre as questões de saúde locais.

O campo de estágio foi inicialmente organizado em uma única unidade do PSF, com a participação de 10 alunos, divididos em cinco duplas, com uma carga horária de quatro horas semanais. Inicialmente, os alunos investiram no conhecimento do funcionamento da unidade e da proposta do PSF, na construção de um vínculo com a equipe de trabalho bem como no reconhecimento do território onde tal equipe atuava.

O grupo de alunos era supervisionado semanalmente pelos professores de Psicologia Comunitária na Universidade. Durante a supervisão, as questões trazidas eram debatidas no sentido de elaborar propostas de intervenção a serem desenvolvidas. Uma vez por mês, a supervisão era realizada no próprio PSF, e, nessas ocasiões, as enfermeiras e os médicos participavam da atividade.

Após um ano de experiência em duas equipes do PSF, o campo de estágio em Psicologia Comunitária se estendeu para outras cinco equipes. Atualmente, temos alunos estagiando em todas as 10 equipes de PSF da cidade. Conforme mencionado, a partir da realidade dos PSFs do Município, delineamos um conjunto de atividades que vêm sendo realizadas.

\section{O acolhimento psicológico}

A partir da identificação de uma significativa demanda de atendimentos na área de saúde mental, estabelecemos um acolhimento psicológico (Kovács, Kobayashi, Santos, \& 
A principal queixa está relacionada a sintomas de ansiedade $e$ depressão $(29,7 \%$ dos casos), mas queixas referentes a problemas de comportamento de crianças e dificuldades no relacionamento familiar também são significativas.
Avancini, 2001; Mahfoud, 1999). Cada dupla de estagiários reserva um período para atender esses casos. Os estagiários também realizam visitas domiciliares - com as agentes comunitárias de saúde - para pessoas que demandam um atendimento psicológico, mas que não têm condições de se deslocar até o serviço de saúde.

Os atendimentos no acolhimento se dão em até quatro encontros, que têm como objetivo acolher o usuário em suas questões, construir um espaço de reflexão sobre os problemas vividos e buscar potencializar as possibilidades de ação que estejam ao seu alcance. Ao acolher o usuário, o estagiário deve estar atento à problemática trazida e realizar uma escuta complexa. Dependendo da situação, o acolhimento envolve também visitas domiciliares, entrevistas com familiares, reuniões na escola da região, parceria com o centro comunitário, contato com o Conselho Tutelar ou delegacia da mulher. Orientamos os alunos a discutirem os casos com a equipe e com o profissional que realizou o encaminhamento. Buscamos, assim, estimular uma abordagem multidisciplinar e intersetorial (Czeresnia \& Freitas, 2003).

Em grande parte dos casos, o acolhimento é suficiente para dar conta da questão colocada, que envolve uma orientação ou um conflito mais pontual. Quando necessário, dependendo das características e da gravidade da situação, recomendamos a psicoterapia e o acompanhamento psiquiátrico. Nessas ocasiões, o usuário é encaminhado ao Ambulatório de Saúde Mental do SUS ou à clínica-escola da Universidade, onde pode ter acesso a atendimento psiquiátrico e a um acompanhamento psicoterapêutico mais prolongado.

No acolhimento psicológico, os estagiários preenchem uma ficha de anamnese, que posteriormente é anexada ao prontuário do paciente. Ao final de cada semestre, tabulamos os dados dessas fichas e elaboramos um relatório de atividades que é entregue à SMS.

No período entre o segundo semestre de 2004 e o primeiro semestre de 2007 , foram atendidas 726 pessoas em acolhimento no PSF. Desse total, a maioria é composta pelo público feminino (65,5\% mulheres e 34,5\% homens). A principal queixa está relacionada a sintomas de ansiedade e depressão (29,7\% dos casos), mas queixas referentes a problemas de comportamento de crianças e dificuldades no relacionamento familiar também são significativas.

Das 726 pessoas atendidas, em 211 casos (29\%), o acolhimento foi resolutivo, no sentido de não ser necessário algum encaminhamento posterior, 141 pessoas (19,4\%) foram encaminhadas para atendimento psicológico na Clínica-escola da USF, 26 (3,5\%) para atendimento no ambulatório de saúde mental, e 152 pessoas (20,9\%) deixaram de ir ao acolhimento antes de seu término. Ainda carecemos de um instrumento que possa avaliar as razões para tal desistência, mas percebemos algumas questões que podem estar envolvidas nessa situação, como a dificuldade de horários, a não adequação do acolhimento às expectativas do paciente, o manejo dado pelo estagiário na sessão e o encaminhamento inadequado do caso por parte dos profissionais do PSF.

A maior parte dos encaminhamentos para o acolhimento $(54,6 \%)$ é feita pelos profissionais do PSF (médicos, enfermeiras e agentes comunitárias de saúde). A divulgação desse tipo de atendimento à comunidade gerou, ao longo do tempo, o surgimento de uma demanda espontânea (25,2\% dos casos). 


\section{Atividades em grupo}

A partir das demandas de acolhimento, bem como do contato com a equipe e a comunidade, levantamos frentes de ação desenvolvidas no estágio. Os projetos poderiam ser desenvolvidos em parceria com algum trabalho já em andamento no PSF ou constituir uma intervenção nova.

Formamos diversos trabalhos com grupos, alguns coordenados apenas pelos estagiários, outros em parceria com profissionais de outras áreas (enfermeiras, ACS, médicos). Desenvolvemos oficinas psicossociais (Afonso, 2006), grupos operativos e de mediação, além de participação em atividades comunitárias, eventos, festejos e palestras. Nas atividades grupais, buscamos mobilizar certos processos psíquicos a partir da constituição dos laços intersubjetivos, o que propicia a ressignificação e o deslocamento de papéis no grupo (PichonRivière, 1994).

No desenvolvimento dos projetos, temos incentivado a aproximação com outros locais, como a escola e os centros comunitários. Dentre as atividades realizadas, temos:

Grupo de obesidade e grupo de hipertensos - desenvolvidos em parceria com médicos, enfermeiros e ACS. Os estagiários trabalham os aspectos psicológicos desses problemas de saúde, contribuindo com uma visão integral do ser humano e de seu processo de adoecimento/sofrimento. É interessante observar que, em alguns grupos mais antigos, o foco passou paulatinamente da discussão sobre a doença em si para uma reflexão e debate sobre a existência cotidiana dos sujeitos do grupo.

Grupo de gestantes - realizado em parceria com a médica e a enfermeira das unidades. Os estagiários desenvolvem algumas dinâmicas de grupo e discussões de temas referentes à área de Psicologia com as gestantes, relação mãe/bebê, abordando tanto as ansiedades inerentes a esse período como as idealizações com relação ao papel materno.

Parceria com a escola e o centro comunitário - realizamos reunióes com professores da escola da região em que são discutidos temas referentes à saúde do escolar. Grupo de adolescentes: realizado nas escolas e em um dos centros comunitários do Município, esse grupo busca diálogar sobre temas como sexualidade e drogas, dentre outros. Tais temas são discutidos a partir da realidade cotidiana dos adolescentes, e buscam fomentar uma reflexão sobre seu contexto de vida, seus projetos e suas expectativas com relação à vida afetivo-sexual.

Grupo de mulheres: realizado com mulheres que apresentam quadro de depressão e ansiedade. No atendimento dessas mulheres, pudemos constatar falas bastante comuns: a precariedade financeira, as brigas com o marido, as dificuldades com a educação dos filhos. Vemos muitas delas sem uma inserção de trabalho, restritas ao ambiente doméstico e enfrentando conflitos familiares. O objetivo de tal grupo é refletir e compartilhar experiências, enfocando as relações pessoais, os projetos de vida, a sexualidade e diversos outros aspectos. O processo de identificação no grupo facilita a construção de vínculos de solidariedade que funcionam como um apoio à mulher, que, mais fortalecida, vai aos poucos experimentando transformar os papéis há tempo determinados em suas relações pessoais.

Projeto Quilombo: ações para aproximar a comunidade do quilombo do PSF através de discussões e atividades realizadas no território.

É importante enfatizar que a discussão em todos os grupos realizados busca articular a singularidade da história de vida do sujeito a 
Trabalhamos

no sentido do

fortalecimento das redes de apoio, considerando que esses aspectos têm um impacto grande na saúde mental dos sujeitos. um contexto social mais amplo. Nesse sentido, procuramos problematizar o processo saúde/ doença no cotidiano de vida das pessoas, desconstruindo representações sobre o papel da mulher e da mãe, a culpabilidade da criança por seu fracasso escolar ou o uso abusivo de drogas como algo desarticulado de uma situação social. Trabalhamos no sentido do fortalecimento das redes de apoio, considerando que esses aspectos têm um impacto grande na saúde mental dos sujeitos (Pitta, 2001; Saraceno, 1999).

Realizamos também grupos com as agentes comunitárias de saúde, que constituem um espaço de apoio onde são discutidas questões relacionadas ao cotidiano de trabalho e que colaboram com a reflexão e a elaboração de algumas questões enfrentadas no dia a dia. Os estagiários buscam abordar aspectos como conflitos na equipe, dificuldades no trabalho com a comunidade, questões relativas à saúde mental e às possibilidades de tratamento e intervenção. Uma questão bastante recorrente nos grupos é a não diferenciação entre o âmbito público e o privado. O fato de morarem no território e também de serem usuárias do serviço facilita tal movimento. Várias ACS também vivem problemas pessoais e familiares semelhantes à população atendida. Em algumas ocasiões, elas acabam por procurar os estagiários para buscar ajuda.

Os integrantes da equipe do PSF lidam cotidianamente com situações muito difíceis, pressões constantes e precariedade das condições de trabalho, que geram uma grande sobrecarga emocional. A discussão no grupo visa a proporcionar melhor compreensão de algumas atuações dos profissionais dentro da equipe e possibilitar a construção de novas formas de lidar com os problemas.
Esses grupos também colaboravam para compreender as dificuldades no trabalho, os boicotes, os problemas de comunicação, as contradições e as ambigüidades. Na supervisão, buscamos desenvolver com os estagiários uma visão mais ampla da dinâmica institucional e de sua relação com a comunidade, de modo a auxiliá-los a se posicionarem nos diversos espaços institucionais.

\section{Ampliação do campo}

A partir do primeiro semestre de 2007, ampliamos o campo de estágio nos PSFs para as áreas de Psicologia Clínica e Psicologia Escolar, que inseriram estagiários inicialmente em duas unidades do Município. Tal ação se deu no sentido tanto de ampliar a formação do aluno de graduação junto ao SUS como de contemplar algumas demandas significativas na saúde pública. O estágio em Psicologia Clínica oferece atendimentos no modelo da psicoterapia breve, em que são realizadas de oito a dez sessões. O encaminhamento é feito a partir do acolhimento psicológico, no qual é avaliada a demanda do paciente e se este pode se beneficiar de um breve encaixe.

O estágio de Psicologia Escolar desenvolve um trabalho de orientação à queixa escolar (Souza, 2007) que visa à compreensão e à problematização da mesma, contemplando a versão dos diferentes participantes da rede na qual surge o problema escolar (criança, família e escola). Com isso, busca-se promover a circulação de informações e reflexões pertinentes à problemática, propiciando releituras e buscando diversas alternativas para solucionar os casos em conjunto. São realizados acolhimentos com a criança e seus familiares, visitas às escolas, coleta de dados em reuniões de pais e alunos e com outros profissionais envolvidos no processo educacional. 
Ainda no primeiro semestre de 2007, iniciamos uma parceria com o CAPS II da cidade (inaugurado em novembro de 2006). A parceria consiste no desenvolvimento de atividades realizadas por docentes e estagiários da área de Psicologia Comunitária e Psicologia Clínica. Temos desenvolvido psicoterapia individual e em grupo, grupos de geração de renda, atendimento familiar e matriciamento das unidades de PSF. Oferecemos também um grupo de estudos aberto aos trabalhadores do serviço, no intuito de construir um espaço de reflexão e formação.

Outra iniciativa importante aconteceu através da participação conjunta dos professores da Universidade e dos técnicos da prefeitura nas reuniões dos Pólos de Educação Permanente. A partir de um seminário sobre saúde mental na atenção básica realizado com os trabalhadores de saúde do Município, elaboramos uma proposta de curso de capacitação, que foi efetuado no segundo semestre de 2006. O curso abrangeu trabalhadores do PSF do Município e da microrregião.

\section{Considerações finais}

A experiência no estágio de Psicologia Comunitária junto ao PSF tem propiciado diversas reflexões sobre o papel do psicólogo na saúde pública. Já nos primeiros contatos com a equipe técnica da prefeitura e do PSF, percebeu-se a expectativa de que a intervenção dos alunos fosse de atendimento em psicoterapia individual. Há uma representação, historicamente definida, sustentada tanto pela população quanto pelas equipes, do atendimento clínico individual como modelo assistencial primordial no campo da saúde, o que reitera um paradigma curativo. Percebemos também que o próprio aluno de graduação ainda tem o enquadre clínico individual como fórum privilegiado (se não único) de atuação do psicólogo. Aprender a fazer essa reversão de demanda e mudar a própria concepção que o imaginário social tem do psicólogo tem sido, talvez, o maior aprendizado dos alunos, professores e funcionários envolvidos no estágio.

Observamos que o estagiário, nos momentos iniciais de atividade no PSF, sofre com o impacto de estar diretamente ligado ao cotidiano de um serviço de saúde, numa realidade muito diferente do contexto de uma clínica-escola e que expõe o aluno às dificuldades da organização do serviço e aos problemas da população. No entanto, a experiência tem mostrado que tal estágio oferece um campo extremamente rico para os alunos, tanto no que diz respeito ao desenvolvimento de atividades com diferentes demandas como ao contato com uma equipe multidisciplinar e com a realidade do território. Constatamos isso a partir da procura que esse campo de estágio tem na opção pela área de Psicologia Comunitária.

No intuito de promover mudanças na formação dos alunos, o curso de Psicologia da USF tem oferecido, nos últimos anos, as disciplinas Psicologia da Saúde e Políticas Públicas, que abordam temas como políticas sociais, epidemiologia, reforma psiquiátrica e atenção psicossocial, problematizando a prática do psicólogo no contexto do SUS e do SUAS (Sistema Único de Assistência Social).

Não descartamos, em hipótese alguma, a importância do trabalho clínico individual; no entanto, consideramos que, no campo da saúde pública, ele deve constar como um recurso dentre uma série de outros dispositivos voltados para uma atenção psicossocial, de modo a não perder de vista a complexidade do fenômeno de sofrimento e adoecimento que se coloca (Amarante, 2000, 2003, 2007; Lobosque, 1997, 2001). 
A princípio, o enquadre individual é visto como lugar de manutenção da privacidade, e o grupo é tomado com desconfiança, como um espaço onde as contribuições dos outros participantes são vislumbradas como uma forma de ataque, e não de ajuda.
Por parte da população, temos encontrado dificuldades na adesão das pessoas a algumas das atividades grupais; muitas vezes, elas alegam desconforto em expor sua vida pessoal para outras pessoas que não o estagiário, principalmente considerando que os freqüentadores do grupo são vizinhos ou conhecidos do bairro. A princípio, o enquadre individual é visto como lugar de manutenção da privacidade, e o grupo é tomado com desconfiança, como um espaço onde as contribuições dos outros participantes são vislumbradas como uma forma de ataque, e não de ajuda. A fragilização do sujeito parece colaborar para esse tipo de percepção.

Em alguns casos, utilizamos atividades mediadoras (dinâmicas ou atividades manuais) no intuito de facilitar o processo de vinculação das pessoas ao grupo e de diminuir o sentimento de perseguição dos integrantes. O fortalecimento de vínculos de solidariedade no grupo ajuda a reverter fantasias de ataque (Pichon-Rivière, 1994) e opera no sentido de constituí-lo como lugar de apoio do sujeito, que normalmente possui uma rede de suporte social bastante restrita e precária.

De modo geral, o estágio nos PSFs tem sido bem avaliado pelas equipes de saúde e pela Secretaria de Saúde do Município. Há, inclusive, em alguns casos, a solicitação de inclusão de mais estagiários ou de ampliação de sua carga horária. Consideramos, no entanto, que o estágio é um campo de formação que colabora com atividades de extensão junto à comunidade. Nesse sentido, a Universidade não deve responder pelas responsabilidades que são do poder público. Nos contatos com o gestor, temos reforçado a necessidade da ampliação da equipe de saúde mental do Município.

A relação do estagiário com a equipe do PSF constitui um aspecto extremamente importante para o desenvolvimento do trabalho. Apesar da restrição de horas no serviço (quatro horas semanais), estimulamos os alunos a discutirem os casos com a equipe. Essa atitude fortalece o entrosamento e o entendimento dos problemas a partir de um outro enfoque, e ajuda, por um lado, a capacitar a equipe do PSF com relação a questões ligadas à saúde mental, e, por outro, a exercitar o aluno a trabalhar em equipe. Buscamos construir um caminho de diálogo e acolhimento para as angústias e aflições vividas pelos usuários, que integre as dores físicas, as dificuldades da vida e as possibilidades de construção de respostas à problemática em questão.

Nesse percurso, temos enfrentado as dificuldades e os riscos de reproduzir um modelo de cisão entre saúde e saúde mental. Na rotina atribulada de trabalho, muitas vezes é mais fácil encaminhar para a Psicologia ou psiquiatria o choro, a lamentação ou os problemas de comportamento. A integralidade se coloca como um desafio a ser construído no cotidiano das práticas concretas dos serviços.

Percebe-se também que as equipes gestoras dos processos de implantação de novos modelos de intervenção em saúde muitas vezes não consideram os aspectos subjetivos que permeiam a ação dos atores envolvidos nesse processo, focalizando apenas questões técnicas, biológicas e racionais. A incorporação de novas formas de trabalhar com a saúde implica a possibilidade de se contemplar os diferentes aspectos e formas de compreensão das questões relativas a essa área (Czeresnia \& Freitas, 2003; Onocko, 2003).

O envolvimento da Universidade em diversos níveis da atenção à saúde e o desenvolvimento de diferentes frentes de atuação (estágio, participação de docentes no colegiado de saúde mental, reuniões com o gestor e coordenadores de saúde, participação no CAPS e no gerenciamento dos PSFs) tem propiciado não só mudanças na formação dos alunos mas também a construção de uma intervenção mais ampla junto à comunidade. 


\section{Carlos Alberto Pegolo da Gama}

Psicólogo, doutorando em Saúde Coletiva (Unicamp); professor da Universidade São Francisco. Professor da Universidade do Vale do Sapucaí.

E-mail: carlosgama@terra.com.br

\section{Mirna Yamazato Koda}

Psicóloga, doutoranda do Departamento de Psicologia Social do Instituto de Psicologia da USP; professora da Universidade São Francisco. Membro do Laboratório de Estudos em Psicanálise e Psicologia Social (LAPSO) do Instituto de Psicologia da USP.

E-mail: mkoda@usp.br

Recebido 24/04/2007 Reformulado 03/10/2007 Aprovado 19/11/2007.

Referências
Afonso, M. L. M. (2006). Oficinas de dinâmica de grupo: um método de intervenção psicossocial. São Paulo: Casa do Psicólogo.

Amarante, P. D. C. (1998). (Org.). Loucos pela vida: a trajetória da reforma psiquiátrica no Brasil. Rio de Janeiro: Ensp/Fiocruz.

Amarante, P. D. C. (1999). Manicômio e loucura no final do século e do milênio. In M. I. A. Fernandes, I. R. Scarcelli, \& E. S. Costa (Orgs.), Fim de século: ainda manicômios? (pp. 47-53). São Paulo: Instituto de Psicologia da Universidade de São Paulo.

Amarante, P. D. C. (2000). O homem e a serpente: outras histórias para a loucura e a psiquiatria. Rio de Janeiro: Fiocruz.

Amarante, P. D. C. (2003). (Org.). Archivos de saúde mental atenção psicossocial (Vol. 1). Rio de Janeiro: Nau Editora.

Amarante, P. D. C. (2007). Saúde mental e atenção psicossocial. Rio de Janeiro: Fiocruz.

Andrade, A. N., \& Araújo, M. D. (2003). Paradoxos das políticas públicas: programa de saúde da família. In Z. A. Trindade \& N. A. Andrade (Orgs.), Psicologia e saúde: um campo em construção. São Paulo: Casa do Psicólogo.

Brasil. (1997). Portaria no 1886/GM. Aprova as normas e diretrizes do programa de agentes comunitários de saúde e do Programa de Saúde da Família, de 18 de dezembro de 1997. Recuperado em 20 de junho de 2006, de http://dtr2004.saude.gov.br/dab/ legislacao/portaria1886_18_12_97.pdf

Campos, R. H. F. (2000). (Org.). Psicologia Social Comunitária: da solidariedade à autonomia. Petrópolis, RJ: Vozes.

Campos, R. H. F., \& Guareschi, P. A. (2000). (Orgs.). Paradigmas em psicologia social: a perspectiva latino-americana. Petrópolis, RJ: Vozes.

Conselho Federal de Psicologia. (1994). Psicólogo brasileiro: práticas emergentes e desafios para a formação. São Paulo: Casa do Psicólogo.

Czeresnia, D., \& Freitas, C. M. (2003). (Orgs.). Promoção da saúde: conceitos, reflexões, tendências. Rio de Janeiro: Fiocruz.

Dimenstein, M. D. B. (1998). O psicólogo nas unidades básicas de saúde: desafios para a formação e atuação profissionais. Estudos de Psicologia, Natal, 3(1), 53-81.
Fernandes, M. I .A., Vicentin, M. C. G., \& Vieira, M. C. T. (2004). (Orgs.). Tecendo a rede: trajetórias da saúde mental em São Paulo. Taubaté, SP: Cabral.

Freitas, M. F. Q. (1998). Inserção na comunidade e análise de necessidades: reflexões sobre a prática do psicólogo. Psicologia: Reflexão e Crítica, 11(1), 175-189. Recuperado em 15 de março de 2006, da Redalyc (Red de Revistas Científicas de América Latina, el Caribe, España y Portugal): http://redalyc. uaemex.mx/redalyc/pdf/188/18811111.pdf

Kovács, M. J., Kobayashi, C., Santos, A. B. B., \& Avancini, D. C. F. (2001). Implantação de um serviço de plantão psicológico numa unidade de cuidados paliativos. Boletim de Psicologia, 51(114), 1-22

Lobosque, A. M. (1997). Princípios para uma clínica antimanicomial. São Paulo: Hucitec.

Lobosque, A. M. (2001). Experiências da loucura. Rio de Janeiro: Garamond.

Mahfoud, M. (1999). (Org.). Plantão psicológico: novos horizontes. São Paulo: Companhia Ilimitada.

Ministério da Saúde (2007). Departamento de atenção básica: números da saúde da família. Recuperado em 22 de setembro de 2007, de http://dtr2004.saude.gov.br/dab/abnumeros. php\# historico

Onocko, R. (2003). Planejamento no labirinto: uma viagem hermenêutica. São Paulo: Hucitec.

Pichon-Rivière, E. (1994). O processo grupal. São Paulo: Martins Fontes.

Pitta, A. (2001). (Org.). Reabilitação psicossocial no Brasil. São Paulo: Hucitec.

Saraceno, B. (1999). Libertando identidades: da reabilitação psicossocial à cidadania possível. Rio de Janeiro: TeCorá.

Souza, B. P. (2007). (Org.). Orientação à queixa escolar. São Paulo: Casa do Psicólogo.

Spink, M. J. P. (2003). Psicologia social e saúde: práticas, saberes e sentidos. Petrópolis, RJ: Vozes.

Spink, M. J. P. (2007). (Org.). A psicologia em diálogo com o SUS: prática profissional e produção acadêmica. São Paulo: Casa do Psicólogo. 